\title{
Study on Vibration Tapping for SiCp/Al Particle-reinforced Metal Matrix Composite
}

\author{
Yang Liu' ${ }^{1}$, and Jing Zhao 2 ,a \\ ${ }^{1}$ Department of Mechanical Engineering and Automation, Beihang University, Beijing 100083 \\ ${ }^{2}$ Institute of Science and Technology, Beihang University, Beijing 100083
}

\begin{abstract}
Aiming at answering the question that low tap service life of ordinary tapping and bad thread quality on particle-reinforced metal matrix composite $\mathrm{SiCp} / \mathrm{Al}$, the reason of question and the mechanism of low-frequency torsional vibration tapping are analyzed. The experiments were carried out to compare the tap service life and the thread quality of vibration tapping with ordinary tapping without cutting fluid. It indicates that vibration tapping could make tapping torque reduce greatly, the tap service life could be prolonged twice comparing with continuous tapping without cutting fluid, and could ensure the good thread quality. Moreover, it promotes metal matrix composite's further application.
\end{abstract}

Keywords: Metal matrix composite; Low-frequency torsional vibration tapping; Tap service life; Thread quality.

\section{Introduction}

Particle-reinforced metal matrix composites generally use $\mathrm{SiC}$, AlN, and $\mathrm{Al}_{2} \mathrm{O}_{3}$ as reinforcement phases, and aluminum with its alloys and magnesium as matrix materials. Meanwhile, they have excellent physical and mechanical properties: high mechanical strengths, excellent thermal stability and low coefficient of linear expansion, etc, and they are widely used in aviation, aerospace, sports and other industries [1]. Particlereinforced metal matrix composites are characterized by isotropy, easy fabrication and relatively low price, and they are the focus of current research on metal matrix composites. However, they are typical difficult-tomachine materials, due to the inclusion of reinforcing particles with high hardness in the matrix, they can result in severe tool wear, low processing accuracy and poor surface quality.

Tapping on difficult-to-machine materials has always been a problem and bottleneck in machining, and it is particularly difficult for composite materials. However, there are few studies on tapping process of particlereinforced metal matrix composites. Solving the tapping process problems of composite materials is of great value for the promotion and application of composite materials. Some researchers used high-speed cutting processes or diamond-coated tools to solve composite materials processing problems ${ }^{[2]}$. However, diamond-coated carbide taps are very rare and expensive which are difficult to be put into use widely in production, so usually only high-speed steel taps could be used for processing. The $\mathrm{SiC}_{\mathrm{p}} / \mathrm{Al}$ composite material herein has a $\mathrm{SiC}$ particle content of $40 \%$ with about $1 \mu \mathrm{m}$ particle diameter and an elastic modulus of $140 \mathrm{GPa}$. Due to lack of effective measures to prevent the tap from breaking, the continuous tapping of machine tool is generally not used. Instead, the skilled workers manually tap. Since the tap wears quickly, it is easy to break the tap due to the excessive tapping torque and results in low processing efficiency and high costs. Therefore, under the existing conditions, improving the process method and prolonging the tap service life are the key issues to solve the $\mathrm{SiC}_{\mathrm{p}} / \mathrm{Al}$ tapping process.

In this paper, a low-frequency torsional vibration tapping experiment was performed on $\mathrm{SiC}_{\mathrm{p}} / \mathrm{Al}$. The results show that low-frequency vibration tapping can significantly make the tapping torque reduce and effectively improve the tap service life and thread quality, which is an effective way to solve the tapping problem of $\mathrm{SiC}_{\mathrm{p}} / \mathrm{Al}$.

\section{Mechanism of vibration tapping increasing the tap service life}

\subsection{Torque characteristics of particle-reinforced composites general tapping}

According to the surface forming mechanism in the

\footnotetext{
a Corresponding author: zhao_jing@buaa.edu.cn
} 
transition cutting process ${ }^{[3-5]}$, due to the existence of the cutting edge fillet, it is inevitable that the elasticity of the machined surface will restore and cause severe friction between the tool flank and workpiece. In the process of tapping $\mathrm{SiC}_{\mathrm{p}} / \mathrm{Al}$ with a high-speed steel tap, the tap wears rapidly because of containing $\mathrm{SiC}$ particles of high hardness in the matrix, as shown in Fig. 1. Then a large obtuse radius is formed and the elastic recovery magnitude of the machined surface increases, which make the friction between the flank of the tap and the workpiece more severe. During the tapping process, numbers of cutting teeth tapping into the bottom hole gradually increases, and the total friction area of the workpiece and the flank face of the blade increases, resulting in a rapid increase in the tapping torque. Therefore, in the tapping of small holes of $\mathrm{SiC}_{\mathrm{p}} / \mathrm{Al}$, the tap is easily broken due to excessive tapping torque, so the tap has a low service life. In addition, if the tapping is performed at a speed of more than $100 \mathrm{r} / \mathrm{min}$, the tap has a sticking knife phenomenon after machining 1 or 2 threaded holes, as shown in Fig.2. The thread profile of tapped is extremely bad in the case of sticking knife, and it is also easy to cause the tap to break.

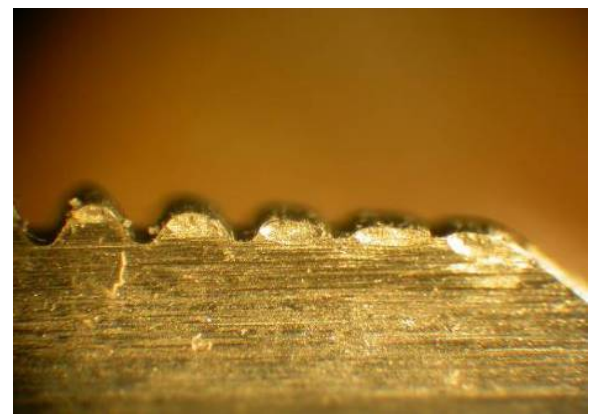

Figure.1 Tap Wear When Tapping SiCp/Al.

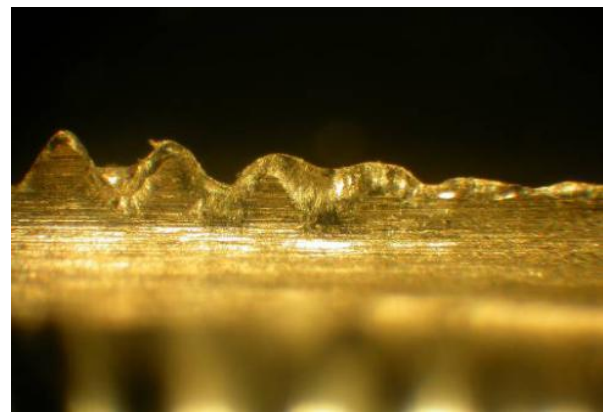

Figure.2 SiCp/Al Sticking Knife Phenomenon.

\subsection{Vibration tapping process features}

In the low-frequency torsional vibration tapping process, the tap has torsional vibration with a revolution relative to the workpiece. The trajectory of the cutting edge is shown in Fig.3. $L_{G}$ is the retreating amount (angle) of the torsional vibration; $L_{T}$ is the cutting amount (angle) per vibration period; $t$ is the time; $\theta$ is the angular displacement of the cutting edge. In a vibration cycle, the cutting edge completes the reverse retraction and starts the positive movement from point $\mathrm{a}$, while the $\mathrm{a}-\mathrm{b}$ section is the distance traveled by the cutting edge in the previous vibration cycle. The cutting edge repeatedly cuts the machined surface, and the position is reached at the end of the last cutting after reaching point $b$. The metal is cut in the b-c section, while the tap is reversed after reaching the c point and the cutting edge is back, finally the tap is rotated forward again into the next vibration cycle after reaching the point $\mathrm{d}$. Therefore, in the vibratory tapping process, the cutting edge of the tap repeatedly cuts the same position on the machined surface of the workpiece a plurality of times, gradually reducing the rebound amount of the machined surface during the process, thereby significantly reducing the friction torque between the processed surface and the back face of the tap caused by violent friction ${ }^{[5,6]}$.

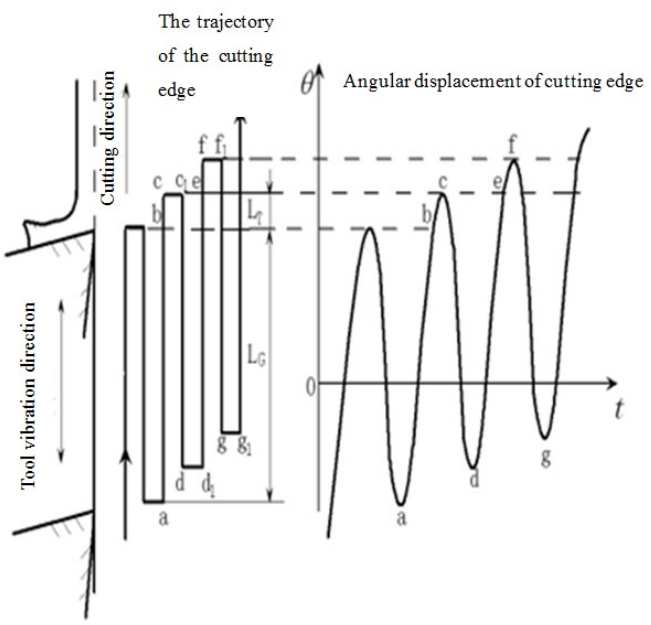

Figure.3 Torsional Vibration Cutting Trajectory of the Cutting Edge.

\section{Determination of experimental conditions}

The experimental system used in this paper is shown in Fig.4. The low-frequency torsional vibration is controlled by the computer-controlled spindle, so the spindle can float freely in the axial direction, and the axial feed is achieved through the self-guidance of the tap during tapping. The workpiece is mounted on the dynamometer. While the tapping torque signal is input to the computer through the dynamic resistance strain gauge and data acquisition card.

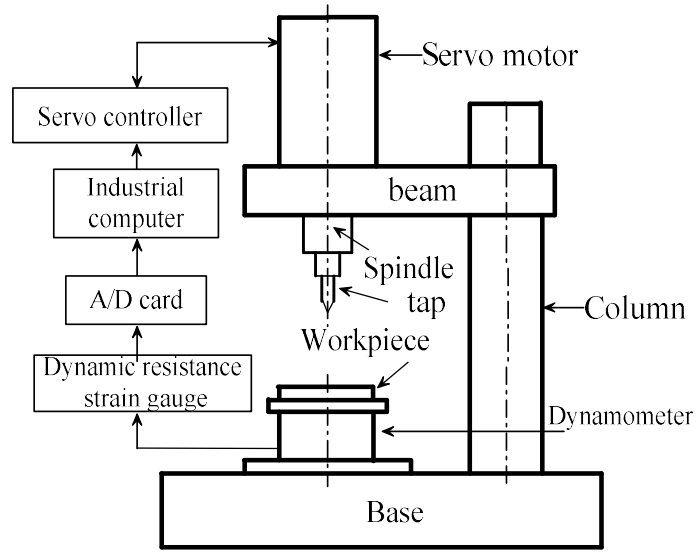

Figure.4 Experiment System. 
The experiments were carried out to compare the tap service life of vibration tapping and general tapping in this paper by using parameters in Table 1. Cutting fluid is an important influencing factor in cutting processing. Related literature has studied the influence of cutting fluid on the cutting process of metal matrix composites. D Mester [7] and others studied the effect of cutting fluid on $\mathrm{Al}-\mathrm{Mg}-\mathrm{SCu} / \mathrm{Al} 2 \mathrm{O} 3$. They argue that cutting fluid aggravates tool wear because the cutting fluid maintains a low temperature in the chip formation area and keeps the material high strength. The study by L Cronjager et al. [8] showed that in drilling and milling of particle-reinforced metal matrix composites, coolant reduced tool life to $1 / 6$ of dry cutting. Therefore, the tap service life of conventional continuous tapping and vibratory tapping were compared without using cutting fluid in the experiment. The processed threaded holes were cut away by wire-electrode cutting to observe the profile of the threads.

Table 1. SiCp/Al Tapping Experimental Conditions.

\begin{tabular}{|c|c|c|}
\hline $\begin{array}{c}\text { Tapping } \\
\text { mold }\end{array}$ & Vibration tapping & $\begin{array}{c}\text { Manually } \\
\text { /continuous tapping }\end{array}$ \\
\hline \multirow{2}{*}{ Tap } & $\begin{array}{c}\text { M3 Machine Taps (High-speed steel, } \\
\text { Kentanium, Grinding taps) }\end{array}$ \\
\hline Bottom hole & \multicolumn{2}{|c|}{$\Phi 2.5 \mathrm{~mm}$, through-hole } \\
\hline $\begin{array}{c}\text { Depth of } \\
\text { tapping }\end{array}$ & \multicolumn{2}{|c|}{$9 \mathrm{~mm}$} \\
\hline \multirow{4}{*}{$\begin{array}{c}\text { Characterist } \\
\text { ics of } \\
\text { tapping } \\
\text { materials }\end{array}$} & Materials & SiCp/A1 \\
\cline { 2 - 3 } & $\begin{array}{c}\text { Elasticity modulus } \\
(\mathrm{GPa})\end{array}$ & 520 \\
\cline { 2 - 3 } & Particle content $(\%)$ & 140 \\
\cline { 2 - 3 } & Particle size $(\mu \mathrm{m})$ & 40 \\
\cline { 2 - 3 } & Density $\left(\mathrm{g} / \mathrm{cm}^{3}\right)$ & 2.9 \\
\hline
\end{tabular}

Considering $\mathrm{SiCp} / \mathrm{Al}$ composites are typical abrasive materials, and excessive repetitive cutting times would exacerbate the wear of the taps, furthermore, if a relatively small amplitude and cutting amount are used, the condition of the separated cutting is not in a good state, so a larger amount of cutting and fewer repetitions of cutting were selected in the experiment.

\section{Experimental results and analysis}

\subsection{Comparison of tap service life in different tapping modes}

As the previous mentioned sticking knife phenomenon during tapping the $\mathrm{SiC}_{\mathrm{p}} / \mathrm{Al}$ material, it leads to poor thread quality, so the criteria for the tap service life should be based on the quality of the tapped thread hole. That is to say: When the tapped threaded hole is inspected with a plug gauge, the pass rule is smooth and the stop rule does not exceed two revolutions; when the threaded hole is thrown away, the thread profile is straightened and the surface quality of the thread is good when viewed with a microscope. The service lives of tapped $\mathrm{SiCp} / \mathrm{Al}$ taps under different parameters are shown in Fig.5.The specific parameters of the corresponding series are shown in Table 2. Taking 400$1.5-40$ as an example, it indicates that the spindle speed is $400 \mathrm{r} / \mathrm{min}$, the pure cutting amount is $1.5^{\circ}$, and the retreat amount is $40^{\circ}$. The meaning of the parameters appearing below can take this as a reference. As shown in Fig.5, the tap service life of vibration tapping is about twice than that of continuous tapping without cutting fluid.



Figure.5 SiCp/Al Tap Life Comparison Chart.

Table 2. Figure 5 Abscissa Corresponding Tapping Parameters.

\begin{tabular}{|c|c|}
\hline $\boldsymbol{1}$ & Manually tapping \\
\hline $\mathbf{2}$ & Continuous tapping \\
\hline $\mathbf{3}$ & $400-1.5-40$ \\
\hline $\mathbf{4}$ & $30-40-135$ \\
\hline $\mathbf{5}$ & $180-40-135$ \\
\hline $\boldsymbol{6}$ & $310-40-135$ \\
\hline $\boldsymbol{7}$ & $180-420-80$ \\
\hline $\boldsymbol{8}$ & $220-420-850$ \\
\hline $\boldsymbol{9}$ & $310-420-850$ \\
\hline
\end{tabular}

\section{Analysis of Results:}

(1) Manual tapping: The main phenomenon in the manual tapping of $\mathrm{SiCp} / \mathrm{Al}$ materials were the excessive tapping torque and the severe tap deformation. In the condition of better neutrality, one threaded hole was processed at most. However, eventually the tap was broken because of excessive torque.

(2) Continuous tapping: When the continuous tapping method was used for the tap service life test, the spindle speed was $30 \mathrm{r} / \mathrm{min}, 180 \mathrm{r} / \mathrm{min}$, and310 r/min, respectively. The tap was broken after tapping seven or eight holes at 30r/min spindle speeds, since the rake face of the tap squeeze out the workpiece material that needs to be removed gradually at the lower cutting speed, which made the $\mathrm{SiC}$ reinforcing particles produce slippage and dislocation. Due to the presence of $\mathrm{SiC}$ reinforcedparticles, the entire machining process was very unstable, the cutting force changes significantly and chipping occurred from time to time. At the same time, the squeezing force on the rake face was also very large during this process, which made the rake face wear too severe, as shown in Fig.1. With the wear of the blade front and back surfaces, the increase of obtuse circle 
radius of blade, the cutter relieving in low speed, the phenomenon of several cutting teeth in front of the tap was more likely to occur during the process of removing the margin by low-speed extrusion, so the squeezing force of the flank and the workpiece also rose sharply, and reinforced-particles also had more severe scratches on the flank, eventually leading to the increase of tapping peak torque. In addition, because the tap correcting tooth almost had no cutting ability, the entire thread cutting amount is reduced, and ultimately the thread passing rule cannot pass or the tap breaks. For $180 \mathrm{r} / \mathrm{min}$ and 310 $\mathrm{r} / \mathrm{min}$, since the speed is high, the phenomenon of sticking knife in the introduction was appeared, the taps were seriously bonded, which made the thread profile incomplete and the thread surface quality reduce.

(3) Vibration Tapping: From the experimental results of several sets of vibration tapping parameters, it could be seen that the tap service life is not very long when the speed is too low or too high. and the reason is the same as the effect of speed in continuous tapping. In addition, the amount of cutting in vibration tapping has a significant effect on the tap service life, which is mainly reflected in the difference value between the forward and backward angles of the tap in each cycle. For $\mathrm{SiCp} / \mathrm{Al}$ materials, the amount of cutting should not be too small. Since the spindle will decelerate in advance when the spindle does not come to the specified angle during each cycle of torsional vibration, and the rotation speed will drop to zero after reaching the known angle, so if the cutting amount is too small, the actual cutting speed of the material is much lower than the specified cutting speed, which has the same effect as the lower cutting speed of continuous tapping on the tap service life, which increases the tapping torque and shortens the tap service life. Too much cutting amounts will result in serious adhesive wear on the tap and reduce thread quality. In conclusion, for the tapping on $\mathrm{SiCp} / \mathrm{Al}$ composites materials, the best method and parameters are: vibration tapping, the parameter is $220-420-850$, which means the spindle speed is $220 \mathrm{r} / \mathrm{min}$, the pure cutting amount is 4200 , and the retraction amount is 8500 . The torque waveform under this parameter is shown in Fig. 6. It can be seen that the peak torque is relatively stable. A partial waveform of the tapping torque waveform is shown in Fig.7, which fully reflects the "retreat-repeated cuttingcutting" stages of the tapping process.

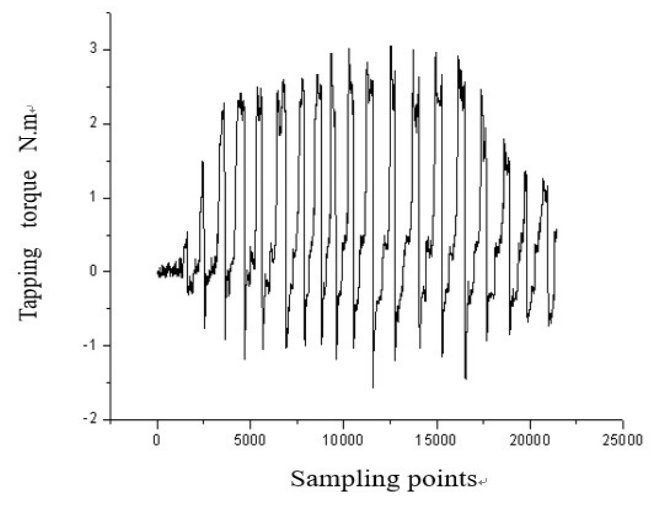

Figure.6 Torque Waveform of Vibration Tapping.

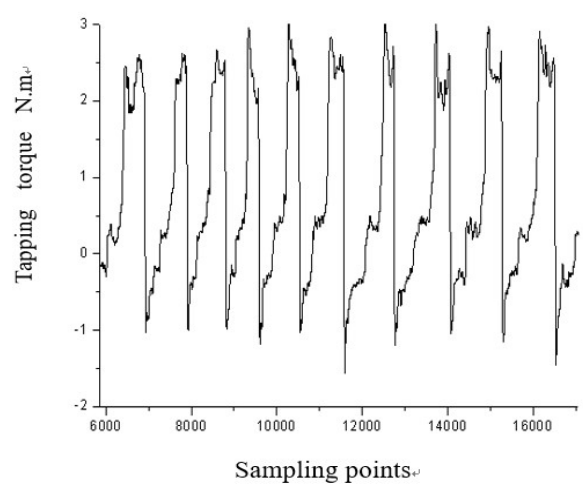

Figure.7 Partial Torque Waveform of Vibration Tapping.

Based on the optimized parameters and tapping methods, the influences of different tool materials on the tapping torque of $\mathrm{SiCp} / \mathrm{Al}$ composites materials were compared in this paper. During the machining of $\mathrm{SiCp} / \mathrm{Al}$ material with carbide taps, the waveform is appeared shown in Fig. 8. With the increase of the tapping hole's depth, the peak torque and back-off torque of the tap both increased. The reason is that the different structure between carbide taps and high-speed steel machine taps. In order to reduce the tapping torque to prevent the tap from breaking, the tap correcting tooth length should be shorten. The tapping waveform of the tap after grinding is shown in Fig.9. It can be seen that the tapping torque of carbide tap after grinding is significantly reduced compared with that of before grinding, and the thread quality is also qualified after inspection, so it can be inferred that the grinding carbide tap is an effective tool for tapping $\mathrm{SiCp} / \mathrm{Al}$ composites materials.

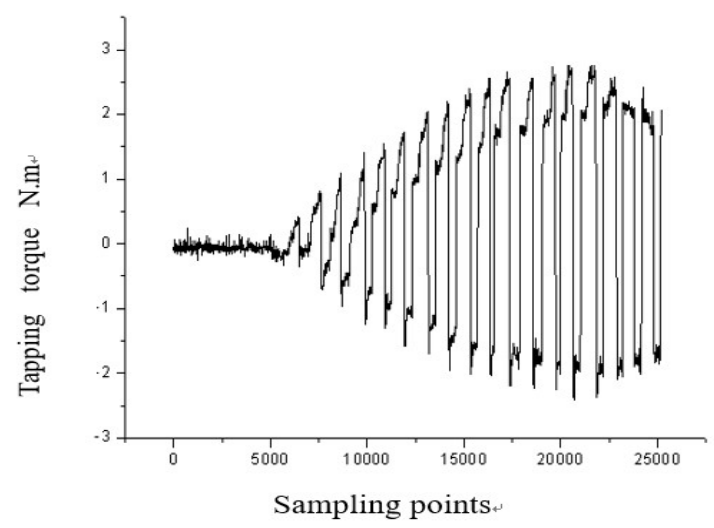

Figure.8 Tapping Waveform of Unpolished Carbide Tap.

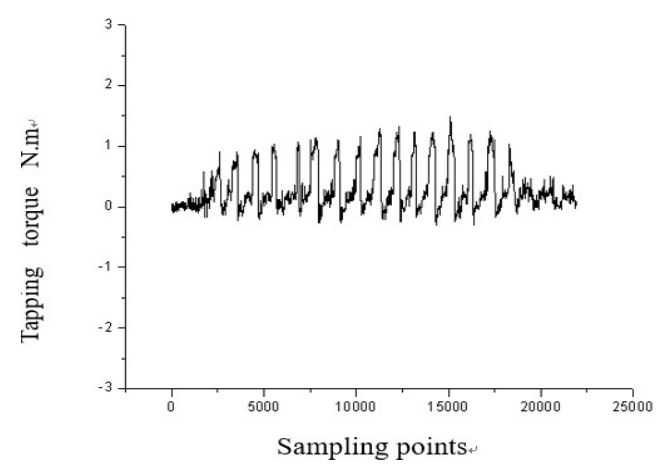

Figure.9 Tapping Waveform of Polished Carbide Tap. 


\subsection{Thread quality comparison of vibration tapping and continuous tapping}

Vibration tapping is a typical interrupted cutting. During the cutting process, the rake face and the chips are continuously separated, making the cutting area open periodically, which is favorable for the discharge of chips; and the amount of pure cutting for vibration tapping is very small, which effectively reduces the friction of contact surface between the blade and chips, lowers the cutting zone temperature , and repeated cutting effectively reduces the rebound amount of the machined surface. Therefore, the sticking knife phenomenon and the problem of pass gauge tightening in low speed continuous tapping thread inspection can be avoided at the same time. The thread profile after a continuous tapping with a spindle speed of $180 \mathrm{r} / \mathrm{min}$ is shown in Fig.10, and that of a vibration tapping at a spindle speed of $220 \mathrm{r} / \mathrm{min}, \mathrm{L}_{T}=420^{\circ}, \mathrm{L}_{G}=850^{\circ}$ after tapping the 20th threaded hole is shown in Fig.11, it can be seen the thread quality is extremely good.

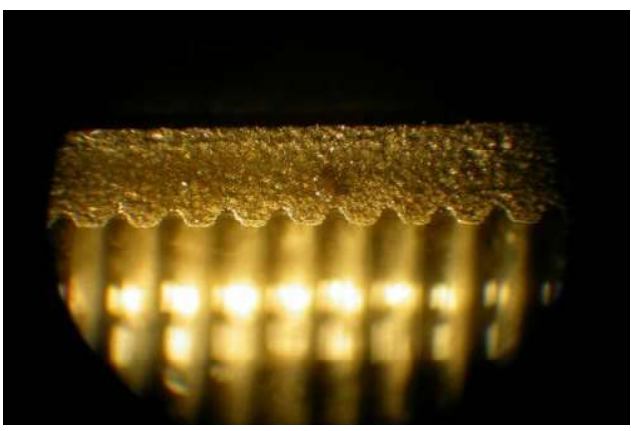

Figure.10 Thread Profile of Continuous Tapping Under the Sticking Knife.

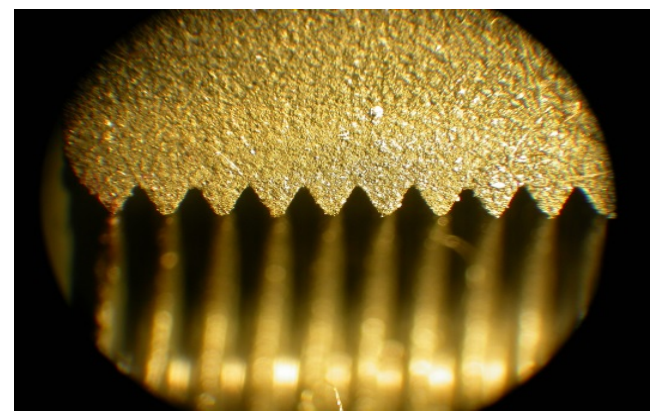

Figure.11 Thread Profile of Vibration Tapping.

\section{Conclusion}

Through the above experimental results and analysis, the following conclusions can be drawn on the application of vibration tapping in $\mathrm{SiCp} / \mathrm{Al}$ composites:
(1) Without the cutting fluid, the vibration tapping method reduces the elastic restoration of the machined surface through repeated cutting. On the one hand, it reduces the friction between the back flank of the tap and the workpiece, and then reduces the tapping torque; On the other hand, it ensures the thread quality and extends the tap service life.

(2) For $\mathrm{SiC}_{\mathrm{p}} / \mathrm{Al}$ composites, the optimization parameters experiment of tap service life was carried out by vibration tapping of large cutting amounts and less repeated cutting times, and the gotten optimal parameter is $220-420-850$, which means spindle speed is $220 \mathrm{r} / \mathrm{min}$, the pure cutting amount is $420^{\circ}$, and the retreating amount is $850^{\circ}$.

(3) Based on the optimized parameters and tapping methods, the influences of different tool materials on the tap service life of $\mathrm{SiCp} / \mathrm{Al}$ composites were compared. In the vibration tapping mode, the grinding carbide taps significantly reduce the tapping torque compared with that of without grinding, and the quality of the tested threads is also acceptable. Therefore, it can be inferred that it is an effective method for tapping $\mathrm{SiCp} / \mathrm{Al}$ composites materials.

\section{References}

1. Debo Li, Yingcai Yao, Zhejun Yuan. Research on special processing of particle-reinforced metal matrix composites [J]. Machinery. 44 (506): 64-68, (2006).

2. Xingxin $\mathrm{Xu}$, Chuanshao Liu, Bo Zhao. Study on cutting force of $\mathrm{SiC}$ particle-reinforced aluminum matrix composites by ultrasonic vibration drilling $[\mathrm{J}]$. Tool Engineering. 41 (1): 49-52 (2007).

3. Zongda Yan. Fundamentals of plastic mechanics [M] Tianjin: Tianjin University Press, (1988).

4. J. B. Martin. Fundamentals and general results of plastic mechanics [M]. Beijing: Beijing Institute of Technology Press, (1990).

5. Deyuan Zhang. Study on Processing and Monitoring Technology of Difficult-to-cut Materials [D]. Beijing: Beihang University, (1993).

6. Fengqi Han. Study on theory and technology of vibration tapping of difficult-to-cut materials [D]. Beijing: Beihang University, (2008).

7. D. Mester, L. Cronjger. Bohren in Faserver startem Aluminium nur Moglich schneiden aus Hartmetal loder PKD, Machinen- mark, Wurzurg, Germany, 23 (23): 28-32, (1989)

8. L.Cronjager. Machining of fible and particlereinforced aluminum[J]. Ann.CIRP. 41 (1): 63-66, (1992). 